\title{
OPPORTUNITIES FOR IMPROVED CARDIOVASCULAR DISEASE PREVENTION IN ONCOLOGY PATIENTS
}

\begin{abstract}
Katia Bravo-Jaimes, MD'; Roselande Marcellon, MA, MPH²; Liubou Varanitskaya ${ }^{3}$; Peter Y. Kim ${ }^{4}$, MD; Cezar Iliescu, MD ${ }^{4}$; Susan C. Gilchrist, MD, MS ${ }^{4}$; Lauren A. Baldassarre, MD ${ }^{5}$; Charlotte Manisty, $\mathrm{MD}^{6}$; Arjun Ghosh, $\mathrm{MD}^{7}$; Avirup Guha, $\mathrm{MD}^{8}$; Juan C. Lopez-Mattei, $\mathrm{MD}^{4}$
\end{abstract}

1 Division of Cardiovascular Medicine. University of Texas Health Science Center at Houston. Houston, Texas, USA.

2 School of Medicine. Albany Medical College. Albany, New York, USA.

3 School of Medicine. Martin Luther University of Halle-Wittenberg. Halle, Germany.

4 Department of Cardiology. University of Texas MD Anderson Cancer Center. Houston, Texas, USA.

5 Section of Cardiovascular Medicine. Yale School of Medicine. New Haven, Connecticut, USA.

6

7

8 Harrington Heart and Vascular Institute. University Hospitals, Case Western Reserve University. Cleveland, Ohio, USA

Word count: 2734 words

Corresponding author:

Juan C. Lopez-Mattei, MD. 
Address:

Department of Cardiology

MD Anderson Cancer Center

1515 Holcombe Blvd, Unit 1451

Houston, TX 77030, USA

Email: Jlopez9@mdanderson.org 


\section{ABSTRACT}

\section{Purpose of review:}

Cancer patients often have cardiovascular risk factors at the time of cancer diagnosis. Current cardiovascular disease prevention guidelines are based on studies that largely excluded these patients. We reviewed and commented on recent data regarding cardiovascular disease prevention in this population.

\section{Recent findings:}

Non-pharmacologic therapies aiming to reduce "lifestyle toxicity" produced by cancer treatments have demonstrated potential to decrease the incidence of adverse outcomes. Exercise before, during and after cancer treatment not only promotes higher quality of life and cardio-respiratory fitness but also reduces adverse cardiovascular outcomes. Lipid and cardiometabolic disease management is paramount, but predominantly based on data that excludes these populations of cancer patients and survivors. Lipids and cardiometabolic disease management is paramount, but predominantly based on data that excludes these populations of cancer patients and survivors.

\section{Summary:}

A comprehensive approach including medical evaluation, prescriptive exercise, cardiac risk factor modification, education, counseling, pharmacologic and behavioral interventions are needed in these patients. These interventions constitute the core of Cardio-Oncology rehabilitation programs, which if implemented appropriately may help reduce cardiovascular events in this population. Knowledge gaps in these areas are starting to be addressed by ongoing clinical trials.

Keywords: cardio-oncology, cardiovascular disease, prevention, cancer survivor 


\section{INTRODUCTION}

Cardiovascular disease (CVD) is an important competing cause of death in cancer survivors ${ }^{1}$. Several factors must be considered in order to establish causal relationships between cancer and the development of CVD: 1) shared risk factors for both ${ }^{2}$; 2) potential cardiotoxicity from cancer treatment (acute, subacute or chronic) ${ }^{3} ; 3$ ) molecular pathways in common ${ }^{4}$; and 4) baseline cardiovascular status ${ }^{5}$. Smoking, alcohol use and environmental toxins have been related to both CVD and certain malignancies ${ }^{2}$. Many oncologic treatments have significant cardiovascular adverse effects, such as anthracyclines, human epidermal growth factor receptor tyrosine kinase (HER2) inhibitors, immune checkpoint inhibitors, antimetabolites and radiation therapy (RT) ${ }^{3,6}$. Newer associations linking cancer and CVD include research regarding senescence $^{7}$ and hematological phenomenon of clonal hematopoiesis of indeterminate potential $^{8}$ that has been associated with CVD. There are no current evidence-based recommendations regarding how to screen survivors for CVD, but there are consensus statement recommendations endorsed by the American Society of Clinical Oncology (ASCO) which defines cancer patients at high risk for cardiac disease ${ }^{9}$ and the National Comprehensive Cancer Network which provides clinical guidelines on healthy lifestyle behaviors for cancer patients and survivors and screening for $C V D^{10}$. Gaps in knowledge include whether current preventive measures such as statins work in cancer patients as in the general population as well as the optimal timing and frequency of established screening protocols to prevent cardiotoxicity. It is our belief that recommendations for screening likely will need to be tailored to specific type of cancer and to treatment modality received. In this mini review, we discuss the ASCO definition of high-risk patient and risk factors. Next, we review risk assessment and mitigation strategies in high-risk patients with emphasis on lifestyle measures and hypertension, which are underappreciated but high value targets of prevention. Finally, we focus on three 
particularly high-risk patient populations: breast cancer patients, childhood cancer survivors and prostate cancer patients who have received antiandrogenic therapy.

\section{CANCER PATIENTS AT HIGH RISK FOR CARDIAC DISEASE}

According to the ASCO Clinical Practice Guidelines ${ }^{9}$, cancer patients considered at high risk for cardiac dysfunction include those who:

- Have had treatment with high-dose anthracyclines (e.g. doxorubicin $\geq 250 \mathrm{mg} / \mathrm{m} 2$, epirubicin $\geq 600 \mathrm{mg} / \mathrm{m} 2$ ), high-dose RT (cumulative dose $\geq 30 \mathrm{~Gy}$ ) where the heart is in the treatment field, and combination lower-dose anthracycline (eg, doxorubicin $<250$ $\mathrm{mg} / \mathrm{m} 2$, epirubicin $<600 \mathrm{mg} / \mathrm{m} 2$ ) and lower dose RT (<30 Gy) where the heart is in the treatment field.

- Have had treatment with lower-dose anthracycline (eg, doxorubicin $<250 \mathrm{mg} / \mathrm{m} 2$, epirubicin $<600 \mathrm{mg} / \mathrm{m} 2$ ) or trastuzumab alone with the presence of any of these risk factors: age greater than or equal to 60 years at the time of cancer treatment, compromised cardiac function [e.g. history of myocardial infarction, low-normal left ventricular ejection fraction (50-55\%), or greater than or equal to moderate valvular heart disease] before or during treatment.

- Are receiving treatment with lower dose anthracyclines (eg, doxorubicin $<250 \mathrm{mg} / \mathrm{m} 2$, epirubicin $<600 \mathrm{mg} / \mathrm{m} 2$ ) followed by trastuzumab.

This guideline has some caveats to consider such as the unknown long-term outcomes of newer cancer therapeutics, cohorts largely restricted to hematologic and breast cancer survivors, insufficient cardiovascular risk data related to advances in mediastinal RT delivery; as well as the challenge in certain cases to differentiate between primary and secondary cardiac dysfunction ${ }^{9}$. 


\section{RISK FACTORS}

\section{- Obesity}

For almost three decades, the American Cancer Society has issued diet and exercise guidelines encouraging cancer survivors to adopt and maintain a healthy lifestyle ${ }^{11}$, which includes maintaining a healthy weight, engaging in regular physical activity, and adopting a dietary pattern high in vegetables, fruits and whole grains ${ }^{12}$. Maintaining a healthy weight and body mass index (BMI) between 18.5 and $25 \mathrm{~kg} / \mathrm{m} 2$ must be purposeful and not related to cancer recurrence ${ }^{12,13}$. Pre-diagnosis $\mathrm{BMI} \geq 30$ is associated with higher risk of death from all causes, including cancer-specific causes as well as CVD in patients with colorectal cancer ${ }^{14}$. In breast cancer survivors, postdiagnosis weight loss was not associated with a lower incidence of CVD; however, an increase in waist circumference increased CVD risk ${ }^{15}$. About $60 \%$ of cancer survivors do not have a healthy dietary pattern, despite evidence of its proven benefits to prevent cancer recurrence ${ }^{16}$

\section{- Blood Pressure}

Hypertension can develop in the acute setting [as seen after administration of high-dose steroids or vascular endothelial growth factor (VEGF) inhibitors] or even years after childhood cancer therapy.

The risk of developing hypertension in childhood cancer survivors is twice that of their healthy siblings ${ }^{17}$, and cancer-related risk factors include abdominal or cranial $\mathrm{RT}^{17}$ and use of steroids ${ }^{18}$ or nephrotoxic agents. In children with acute lymphoblastic leukemia treated with high-dose steroids, hypertension is noted in the vast majority, with $16 \%$ of them requiring antihypertensive drugs ${ }^{18}$ and taking up to 5 years to return to baseline ${ }^{19}$. Additionally, since the prevalence of metabolic syndrome is high in childhood cancer survivors, hypertension is expected to develop three or four decades later ${ }^{20}$. 
Anti-VEGF monoclonal antibodies and tyrosine kinase inhibitors have been associated with higher incidence of hypertension (36\% and $25 \%$, respectively $)^{21}$. The pathogenesis involves reduced nitric oxide production in the arterial wall myocytes, increase in endothelin-1, renal vasoconstriction and impaired natriuresis leading to systemic increase in peripheral resistance ${ }^{22}$. Hypertensive emergencies are noted in about $2 \%$ of patients who use bevacizumab, with normalization of blood pressure shortly after

treatment in most cases ${ }^{23,24}$, however certain reports of cardiovascular events have been published in both the acute ${ }^{25}$ as well as long-term settings ${ }^{26}$. Future studies are needed to determine the long-term implications of these medications in the development of cardiovascular events.

\section{- Cholesterol}

The current cholesterol guidelines ${ }^{27}$ reflect evidence collected on non-cancer patients as cancer would likely constitute part of the exclusion criteria in several studies partly due to a shorter expected survival time ${ }^{28}$. Additionally, the pooled cohort equation used to guide lipid lowering therapy cannot adequately account for specific risks such as mediastinal irradiation or cancer therapies associated with cardiovascular events ${ }^{29}$. Thus, lipid management in cancer patients and survivors remains challenging in the absence of specific clinical studies ${ }^{30}$.

\section{- Smoking}

The benefits of smoking cessation in cancer survivors has also been reported. In breast cancer survivors, post-diagnosis quitters had $20 \%$ lower risk of cardiovascular death and $9 \%$ lower risk of all-cause death. The risk of cardiovascular death was also proportionally lower according to the duration of smoking cessation and the amount of smoking $^{31}$. 


\section{RISK ASSESSMENT}

Oncologists rely on the use of various measurement tools that assess functional capacity like the Eastern Cooperative Oncology Group (ECOG) or Karnofsky Performance Status (KPS) scales to determine the suitability of cancer patients to undergo systemic treatment ${ }^{32}$. ECOG uses a 5 -point scoring system and KPS uses a linear score from 0 to 100; with lower overall scores corresponding with increased risk for chemotherapy toxicities and poorer outcomes ${ }^{33}$. Both scales have good inter-rater reliability among oncology healthcare professionals ${ }^{33,34}$. A linear and moderate association between KPS and the New York Heart Association Classification (NYHA) classes $\mathrm{I}-\mathrm{III}{ }^{35}$ has been noted, offering the potential to incorporate data from routinely used scales in monitoring the development of cardiovascular events among cancer patients and survivors. For a more objective measurement of cardiopulmonary safety prior to starting lifestyle interventions, a baseline cardiopulmonary stress test is recommended ${ }^{29}$. In the absence of this technology, a six-minute walk or sit-to-stand tests are good alternatives ${ }^{36}$.

Coronary artery calcium (CAC) score has a potential role in cardiovascular risk assessment of cancer patients since it has the ability to predict cardiovascular events in asymptomatic individuals ${ }^{37}$. Strengths include the ease in which the score can be calculated and age/sex/race specific percentile calculation associated with the score ${ }^{37}$. In the general population, tailored preventive treatment by using CAC score improves systolic blood pressure control, lowers LDL and waist circumference without increasing downstream medical costs ${ }^{38}$. CAC scoring thus can be useful for risk stratification prior to statin treatment and monitoring for the development of cardiotoxic effects in patients exposed to mediastinal radiation or high-risk chemotherapeutics ${ }^{39-}$ 41.

\section{MITIGATING CVD RISK IN HIGH-RISK CANCER PATIENTS}


The following interventions constitute the foundation for Cardio-Oncology Rehabilitation Programs, which using lifestyle and pharmacologic interventions focus on maintenance of cardiorespiratory fitness and CVD prevention in cancer patients undergoing treatment as well as survivors $^{29}$ (Figure 1).

\section{- Non-pharmacologic interventions}

The benefits of physical activity have been mostly studied in cancer survivors who retain the ability to engage in at least moderate exercise. In breast cancer survivors, exercising on average 3.5 hours a week (mostly walking) was protective against metabolic syndrome ${ }^{42}$ and also produced a $41 \%$ lower risk of all-cause mortality ${ }^{43}$. Similarly, in colon cancer survivors, increasing functional capacity from less than 3 to 3 - 8.9 metabolic equivalents per week was associated with $49 \%$ lower risk of all-cause mortality ${ }^{44}$. Furthermore, a metaanalysis of randomized controlled trials including 3632 cancer patients and survivors demonstrated that exercise significantly improved cardio-respiratory fitness with greater benefit achieved when using individualized prescriptive exercise rather than a standard scheduling ${ }^{45}$.

Comparable to the general population, adherence to Mediterranean diet is inversely associated with incident diabetes or CVD in cancer survivors ${ }^{46}$. Other diets such as caloric restriction have also shown protection from anthracycline related toxicity in rodent models through a mechanism of "differential stress resistance" ${ }^{47}$. Further studies in humans are needed to prove the cardiovascular benefits of this latter strategy.

\section{- Pharmacologic interventions}

Hypertension management follows current guidelines ${ }^{48}$; with betablockers or reninangiotensin-aldosterone system inhibitors as first-line treatments due to their potential to prevent cardiomyopathy ${ }^{49}$. Use of non-dihydropyridine calcium channel blockers 
concomitantly with VEGF inhibitors is not recommended due to the risk of increasing chemotherapeutic levels secondary to cytochrome P450 3A4 inhibition ${ }^{50,51}$.

Despite the limitations of the pooled cohort equation, cholesterol management in cancer patients and survivors follows current guidelines ${ }^{27}$. In addition to initiating moderate-intensity statins in those with a 10-year atherosclerotic cardiovascular disease (ASCVD) risk $\geq 7.5 \%$, we favor statins use in women who have undergone left-sided RT to the breast ${ }^{30}$. Recommendations for these medications in women who have received anthracyclines with or without trastuzumab is being assessed in current randomized clinical trials (SBSBC studyNCT03971019, NCT02096588).

\section{SPECIFIC POPULATIONS}

\section{- Breast cancer}

Breast cancer mortality has decreased nearly $40 \%$ during the last 4 decades and currently CVD is the leading cause of death in this population ${ }^{1}$, with heart failure being the most common form ${ }^{52}$. Traditional CVD risk factors are highly prevalent prior to breast cancer diagnosis and potentiate the development of cardiotoxicity ${ }^{53,54}$, which has been largely associated with exposure to anthracyclines ${ }^{55}$ and HER2 inhibitors ${ }^{56}$. Furthermore, the decline in cardiorespiratory fitness, high levels of stress and poor dietary patterns constituting "lifestyle toxicity" resulting from cancer therapy are also responsible for an increase in CVD in this population ${ }^{1,57}$.

Strategies to reduce cardiotoxicity in the short term include anthracycline dose reduction, continuous infusion (instead of bolus), liposomal formulation and use of dexrazoxane ${ }^{56}$. Small clinical trials have also examined the role of pharmacologic prevention of anthracyclines and trastuzumab-induced cardiotoxicity, demonstrating the benefits of carvedilol, lisinopril ${ }^{49}$ or candesartan use ${ }^{58}$. The use of incremental aerobic exercise 
programs have also shown to improve peak VO2 during chemotherapy ${ }^{59}$ and when combined with resistance training improve insulin resistance in breast cancer survivors ${ }^{60}$. The use of Cardio-Oncology rehabilitation programs can help individualize exercise prescriptions and other interventions for these patients ${ }^{29,30}$.

\section{- Childhood cancer survivors}

Approximately $83 \%$ of the 12,000 children and adolescents diagnosed with cancer every year in the United States will survive 5 years or longer ${ }^{61,62}$. Childhood cancer survivors are eight times more likely to die of CVD and 15 times more likely to have heart failure than their contemporaries, and this risk remains elevated beyond 50 years of age ${ }^{63-65}$. Exposure to anthracyclines, cyclophosphamide, mitoxantrone and chest RT are some of the most well-documented risk factors for cardiomyopathy, which is the most prevalent type of CVD among this population ${ }^{66}$. Additionally, those with a history of cranial RT are at highest risk for metabolic syndrome due to the damage of the hypothalamic-pituitary axis and thyroid glands, affecting metabolism, growth hormone $(\mathrm{GH})$ production and satiety feedback mechanisms ${ }^{61}$.

Only about $40 \%$ of survivors follow lifetime screening according to the Children's Oncology Group ${ }^{20}$ and American Heart Association Scientific Statement ${ }^{61,67}$, urging the need for better implementation strategies and public health education regarding preventative strategies in Cardio-Oncology. Lifestyle modifications according to the World Cancer Research Fund/American Institute of Cancer Research guidelines are effective in lowering cardiometabolic risk in this population ${ }^{68}$. In young adult survivors of acute lymphoblastic leukemia with $\mathrm{GH}$ deficiency, $\mathrm{GH}$ replacement decreased the prevalence of metabolic syndrome, improved high-density lipoprotein cholesterol levels and apolipoprotein B/A1 ratios without affecting left ventricular systolic function, quality of life or physical activity ${ }^{69}$. Other pharmacological strategies to prevent cardiotoxicity have not been successful, with two small trials examining the use enalapril for the 
treatment of asymptomatic left ventricular systolic dysfunction not showing long-term benefits $^{70,71}$. The effect of statins on long-term cardiovascular outcomes has not been studied in this population, but its use is recommended according to the most recent guidelines $^{27}$.

\section{- Cardiometabolic risk of antiandrogenic therapy in prostate cancer}

Androgen deprivation therapy (ADT) is achieved surgically via bilateral orchiectomy or medically via gonadotropin-releasing hormone $(\mathrm{GnRH})$ agonists, antagonists, combined androgen blockade or antiandrogens ${ }^{72-76}$. Despite the survival benefits gained, a growing body of research suggests increased risk for adverse metabolic effects and cardiovascular events $^{72-76}$. The development of abdominal obesity ${ }^{72-74}$; increases in total cholesterol, LDL and triglycerides ${ }^{72-74}$; insulin resistance along with higher fasting plasma glucose and glycosylated hemoglobin levels have been noted within few months of ADT initiation ${ }^{72,73}$. Unlike metabolic syndrome in the general population, ADT doesn't seem to change inflammatory markers like C-reactive protein or blood pressure ${ }^{72}$. ADT appears to confer risk for CVD regardless of treatment duration but based on modality. In this way, orchiectomy is associated with only increased risk of diabetes incidence whereas luteinizing hormone releasing hormone and $\mathrm{GnRH}$ agonists have $20 \%$ increased risk of $\mathrm{CVD}^{73}$. Shorter times to fatal myocardial infarction were observed in men aged 65 and older receiving ADT for six months compared to controls; these differences remained when comparing shorter duration of $\mathrm{ADT}^{74}$. Older patients on $\mathrm{ADT}$ and those with preexisting CVD are at increased risk for further cardiovascular complications ${ }^{73,74}$. The bulk of evidence of increased risk of major cardiovascular events in cancer patients with ADT, although bio-plausible, is contradictory ${ }^{73,75}$. The RADICAL-PC study suggested that patients undergoing ADT had similar Framingham risk scores than controls after adjustment for confounders ${ }^{77}$. The PRONOUNCE ${ }^{78}$ study will investigate long-term CVD 
outcomes in patients receiving $\mathrm{GnRH}$ receptor agonist (leuprolide) or antagonist (degarelix).

\section{CONCLUSION}

Cancer patients are an underrepresented population in current cardiovascular disease prevention studies. Non-pharmacologic interventions, mainly focusing on exercise and healthy nutrition, not only improve quality of life and reduce cancer recurrence risk but may also improve overall cardiovascular outcomes. Hypertension is managed per current guidelines for the general population, although betablockers and renin-angiotensin-aldosterone system inhibitors are preferred initial therapies. Further studies focusing on pharmacologic strategies for dyslipidemia are needed to evaluate if current lipid targets are appropriate and sufficient in these patients

\section{KEY POINTS}

- Cardiovascular disease is a competing cause of death in cancer survivors.

- Healthy nutrition and exercise prescriptions during and after cancer treatment contribute to maintenance of cardio-respiratory fitness and may help reduce the incidence of adverse cardiovascular outcomes.

- Hypertension is managed according to current guidelines, with betablockers and reninangiotensin-aldosterone system inhibitors as first-line options.

- Evidence-based treatments for dyslipidemia in this specific population are yet to be defined. 


\title{
ACKNOWLEDGMENTS
}

Acknowledgments \& financial support/sponsorship: None

\author{
Conflicts of interest: None
}




\section{REFERENCES}

1. Kirkham AA, Beaudry RI, Paterson DI, Mackey JR, Haykowsky MJ. Curing breast cancer and killing the heart: A novel model to explain elevated cardiovascular disease and mortality risk among women with early stage breast cancer. Progress in cardiovascular diseases. Mar - Apr 2019;62(2):116-126.

2. Koene RJ, Prizment AE, Blaes A, Konety SH. Shared Risk Factors in Cardiovascular Disease and Cancer. Circulation. 2016;133(11):1104-1114.

3. Herrmann J. Adverse cardiac effects of cancer therapies: cardiotoxicity and arrhythmia. Nature Reviews Cardiology. 2020:1-29.

4. Masoudkabir F, Sarrafzadegan N, Gotay C, et al. Cardiovascular disease and cancer: Evidence for shared disease pathways and pharmacologic prevention. Atherosclerosis. Aug 2017;263:343351.

5. Aboumsallem JP, Moslehi J, de Boer RA. Reverse Cardio-Oncology: Cancer Development in Patients With Cardiovascular Disease. Journal of the American Heart Association. Jan 21 2020;9(2):e013754.

6. Herrmann J. Vascular toxic effects of cancer therapies. Nature Reviews Cardiology. 2020:1-20.

7. Ferrucci L, Fabbri E. Inflammageing: chronic inflammation in ageing, cardiovascular disease, and frailty. Nature Reviews Cardiology. 2018;15(9):505-522.

8. Jaiswal S, Natarajan P, Silver AJ, et al. Clonal Hematopoiesis and Risk of Atherosclerotic Cardiovascular Disease. New England Journal of Medicine. 2017;377(2):111-121.

9. Armenian SH, Lacchetti C, Barac A, et al. Prevention and Monitoring of Cardiac Dysfunction in Survivors of Adult Cancers: American Society of Clinical Oncology Clinical Practice Guideline. Journal of clinical oncology : official journal of the American Society of Clinical Oncology. Mar 10 2017;35(8):893-911.

10. Denlinger CS, Sanft T, Baker KS, et al. Survivorship, version 2.2018, NCCN clinical practice guidelines in oncology. Journal of the National Comprehensive Cancer Network. 2018;16(10):1216-1247.

11. Kushi LH, Doyle C, McCullough M, et al. American Cancer Society Guidelines on nutrition and physical activity for cancer prevention: reducing the risk of cancer with healthy food choices and physical activity. CA: a cancer journal for clinicians. Jan-Feb 2012;62(1):30-67.

12. Rock CL, Doyle C, Demark-Wahnefried W, et al. Nutrition and physical activity guidelines for cancer survivors. CA: a cancer journal for clinicians. Jul-Aug 2012;62(4):243-274.

13. Smith JL, Malinauskas BM, Garner KJ, Barber-Heidal K. Factors contributing to weight loss, nutrition-related concerns and advice received by adults undergoing cancer treatment. Advances in medical sciences. 2008;53(2):198-204.

14. Meyerhardt JA, Giovannucci EL, Ogino S, et al. Physical activity and male colorectal cancer survival. Archives of internal medicine. Dec 14 2009;169(22):2102-2108.

15. Cespedes Feliciano EM, Kwan ML, Kushi LH, Weltzien EK, Castillo AL, Caan BJ. Adiposity, postdiagnosis weight change, and risk of cardiovascular events among early-stage breast cancer survivors. Breast cancer research and treatment. Apr 2017;162(3):549-557.

16. Karavasiloglou N, Pestoni G, Wanner M, Faeh D, Rohrmann S. Healthy lifestyle is inversely associated with mortality in cancer survivors: Results from the Third National Health and Nutrition Examination Survey (NHANES III). PloS one. 2019;14(6):e0218048.

17. Meacham LR, Chow EJ, Ness KK, et al. Cardiovascular risk factors in adult survivors of pediatric cancer--a report from the childhood cancer survivor study. Cancer epidemiology, biomarkers \& 
prevention : a publication of the American Association for Cancer Research, cosponsored by the American Society of Preventive Oncology. Jan 2010;19(1):170-181.

18. Esbenshade AJ, Simmons JH, Koyama T, Koehler E, Whitlock JA, Friedman DL. Body mass index and blood pressure changes over the course of treatment of pediatric acute lymphoblastic leukemia. Pediatric blood \& cancer. Mar 2011;56(3):372-378.

19. Chow EJ, Pihoker C, Hunt K, Wilkinson K, Friedman DL. Obesity and hypertension among children after treatment for acute lymphoblastic leukemia. Cancer. Nov 15 2007;110(10):2313-2320.

20. Children's Oncology Group: Long-term follow-up guidelines for survivors of childhood, version 5.0. http://www.survivorshipguidelines.org.

21. Zarifa A, Albittar A, Kim PY, et al. Cardiac toxicities of anticancer treatments: chemotherapy, targeted therapy and immunotherapy. Current opinion in cardiology. Jul 2019;34(4):441-450.

22. Kamba T, McDonald DM. Mechanisms of adverse effects of anti-VEGF therapy for cancer. British journal of cancer. Jun 18 2007;96(12):1788-1795.

23. Abi Aad S, Pierce M, Barmaimon G, Farhat FS, Benjo A, Mouhayar E. Hypertension induced by chemotherapeutic and immunosuppresive agents: a new challenge. Critical reviews in oncology/hematology. Jan 2015;93(1):28-35.

24. Senkus E, Jassem J. Cardiovascular effects of systemic cancer treatment. Cancer treatment reviews. Jun 2011;37(4):300-311.

25. Sudasena D, Balanescu DV, Donisan T, et al. Fulminant Vascular and Cardiac Toxicity Associated with Tyrosine Kinase Inhibitor Sorafenib. Cardiovascular toxicology. Aug 2019;19(4):382-387.

26. Paschke L, Lincke T, Muhlberg K, Lindner TH, Paschke R. Myocardial Infarction after Long-Term Treatment with a Tyrosine Kinase Inhibitor (TKI) with Anti-VEGF Receptor Activity. Case reports in endocrinology. 2019;2019:7927450.

27. Grundy SM, Stone NJ, Bailey AL, et al. 2018 AHA/ACC/AACVPR/AAPA/ABC/ACPM/ADA/AGS/APhA/ASPC/NLA/PCNA Guideline on the Management of Blood Cholesterol: A Report of the American College of Cardiology/American Heart Association Task Force on Clinical Practice Guidelines. Journal of the American College of Cardiology. Jun 25 2019;73(24):e285-e350.

28. Oren O BR, Cainzos Achirica M, Kopecky SL. Dyslipidemia in Cancer Patients - Evolving Context, New Challenges. 2019; https://www.acc.org/latest-incardiology/articles/2019/09/04/06/43/dyslipidemia-in-cancer-patients. Accessed March 11, 2020.

29. Gilchrist SC, Barac A, Ades PA, et al. Cardio-Oncology Rehabilitation to Manage Cardiovascular Outcomes in Cancer Patients and Survivors: A Scientific Statement From the American Heart Association. Circulation. May 21 2019;139(21):e997-e1012.

30. Yin AB BA, Barac A, Thoman W, Oeffinger KC, Gilchrist SC. Cardiovascular Prevention Strategies in Breast Cancer. JACC: CardioOncology. 2019;1(2).

31. Passarelli MN, Newcomb PA, Hampton JM, et al. Cigarette Smoking Before and After Breast Cancer Diagnosis: Mortality From Breast Cancer and Smoking-Related Diseases. Journal of clinical oncology : official journal of the American Society of Clinical Oncology. Apr 20 2016;34(12):1315-1322.

32. Kelly CM, Shahrokni A. Moving beyond Karnofsky and ECOG Performance Status Assessments with New Technologies. Journal of oncology. 2016;2016:6186543.

33. Azam F, Latif MF, Farooq A, et al. Performance Status Assessment by Using ECOG (Eastern Cooperative Oncology Group) Score for Cancer Patients by Oncology Healthcare Professionals. Case reports in oncology. Sep-Dec 2019;12(3):728-736.

34. Chow R, Bruera E, Temel JS, Krishnan M, Im J, Lock M. Inter-rater reliability in performance status assessment among healthcare professionals: an updated systematic review and meta- 
analysis. Supportive care in cancer : official journal of the Multinational Association of Supportive Care in Cancer. Jan 32020.

35. Johnson MJ, Bland JM, Davidson PM, et al. The relationship between two performance scales: New York Heart Association Classification and Karnofsky Performance Status Scale. Journal of pain and symptom management. Mar 2014;47(3):652-658.

36. Schmidt K, Vogt L, Thiel C, Jager E, Banzer W. Validity of the six-minute walk test in cancer patients. International journal of sports medicine. Jul 2013;34(7):631-636.

37. Blaha MJ, Mortensen MB, Kianoush S, Tota-Maharaj R, Cainzos-Achirica M. Coronary Artery Calcium Scoring: Is It Time for a Change in Methodology? JACC. Cardiovascular imaging. Aug 2017;10(8):923-937.

38. Rozanski A, Gransar H, Shaw LJ, et al. Impact of coronary artery calcium scanning on coronary risk factors and downstream testing the EISNER (Early Identification of Subclinical Atherosclerosis by Noninvasive Imaging Research) prospective randomized trial. Journal of the American College of Cardiology. Apr 12 2011;57(15):1622-1632.

39. Milgrom SA, Varghese B, Gladish GW, et al. Coronary Artery Dose-Volume Parameters Predict Risk of Calcification After Radiation Therapy. Journal of cardiovascular imaging. Oct 2019;27(4):268-279.

40. Layoun ME, Yang EH, Herrmann J, et al. Applications of Cardiac Computed Tomography in the Cardio-Oncology Population. Current treatment options in oncology. May 6 2019;20(6):47.

41. Cuddy S PD, Murphy DJ, Dunne RM, Bueno R, Blankstein R, Di Carli M, Mehra MR, Nohria A, Groarke JD. Incidental Coronary Artery Calcification in Cancer Imaging. J Am Coll Cardiol CardioOnc. . 2019;1(1):135-137.

42. Bao PP, Zheng $\mathrm{Y}$, Nechuta $\mathrm{S}$, et al. Exercise after diagnosis and metabolic syndrome among breast cancer survivors: a report from the Shanghai Breast Cancer Survival Study. Cancer causes \& control : CCC. Sep 2013;24(9):1747-1756.

43. Ibrahim EM, Al-Homaidh A. Physical activity and survival after breast cancer diagnosis: metaanalysis of published studies. Medical oncology. Sep 2011;28(3):753-765.

44. Meyerhardt JA, Giovannucci EL, Holmes MD, et al. Physical activity and survival after colorectal cancer diagnosis. Journal of clinical oncology : official journal of the American Society of Clinical Oncology. Aug 1 2006;24(22):3527-3534.

45. Scott JM, Zabor EC, Schwitzer E, et al. Efficacy of Exercise Therapy on Cardiorespiratory Fitness in Patients With Cancer: A Systematic Review and Meta-Analysis. Journal of clinical oncology: official journal of the American Society of Clinical Oncology. Aug 1 2018;36(22):2297-2305.

46. Freisling $\mathrm{H}$, Viallon $\mathrm{V}$, Lennon $\mathrm{H}$, et al. Lifestyle factors and risk of multimorbidity of cancer and cardiometabolic diseases: a multinational cohort study. BMC medicine. Jan 10 2020;18(1):5.

47. Raffaghello L, Lee C, Safdie FM, et al. Starvation-dependent differential stress resistance protects normal but not cancer cells against high-dose chemotherapy. Proceedings of the National Academy of Sciences of the United States of America. Jun 17 2008;105(24):8215-8220.

48. Whelton PK, Carey RM, Aronow WS, et al. 2017 ACC/AHA/AAPA/ABC/ACPM/AGS/APhA/ASH/ASPC/NMA/PCNA Guideline for the Prevention, Detection, Evaluation, and Management of High Blood Pressure in Adults: A Report of the American College of Cardiology/American Heart Association Task Force on Clinical Practice Guidelines. Journal of the American College of Cardiology. May 15 2018;71(19):e127-e248.

49. Guglin M, Krischer J, Tamura R, et al. Randomized Trial of Lisinopril Versus Carvedilol to Prevent Trastuzumab Cardiotoxicity in Patients With Breast Cancer. Journal of the American College of Cardiology. Jun 11 2019;73(22):2859-2868.

50. Suter TM, Ewer MS. Cancer drugs and the heart: importance and management. European heart journal. Apr 2013;34(15):1102-1111. 
51. Souza VB, Silva EN, Ribeiro ML, Martins Wde A. Hypertension in patients with cancer. Arquivos brasileiros de cardiologia. Mar 2015;104(3):246-252.

52. Riihimaki M, Thomsen H, Brandt A, Sundquist J, Hemminki K. Death causes in breast cancer patients. Annals of oncology : official journal of the European Society for Medical Oncology. Mar 2012;23(3):604-610.

53. Simon MS, Beebe-Dimmer JL, Hastert TA, et al. Cardiometabolic risk factors and survival after breast cancer in the Women's Health Initiative. Cancer. Apr 15 2018;124(8):1798-1807.

54. Park NJ, Chang Y, Bender C, et al. Cardiovascular disease and mortality after breast cancer in postmenopausal women: Results from the Women's Health Initiative. PloS one. 2017;12(9):e0184174.

55. Zhang S, Liu X, Bawa-Khalfe T, et al. Identification of the molecular basis of doxorubicin-induced cardiotoxicity. Nature medicine. Nov 2012;18(11):1639-1642.

56. Chang HM, Moudgil R, Scarabelli T, Okwuosa TM, Yeh ETH. Cardiovascular Complications of Cancer Therapy: Best Practices in Diagnosis, Prevention, and Management: Part 1. Journal of the American College of Cardiology. Nov 14 2017;70(20):2536-2551.

57. Jones LW, Courneya KS, Mackey JR, et al. Cardiopulmonary function and age-related decline across the breast cancer survivorship continuum. Journal of clinical oncology : official journal of the American Society of Clinical Oncology. Jul 10 2012;30(20):2530-2537.

58. Gulati G, Heck SL, Ree AH, et al. Prevention of cardiac dysfunction during adjuvant breast cancer therapy (PRADA): a $2 \times 2$ factorial, randomized, placebo-controlled, double-blind clinical trial of candesartan and metoprolol. European heart journal. Jun 1 2016;37(21):1671-1680.

59. Hornsby WE, Douglas PS, West MJ, et al. Safety and efficacy of aerobic training in operable breast cancer patients receiving neoadjuvant chemotherapy: a phase II randomized trial. Acta oncologica. Jan 2014;53(1):65-74.

60. Knobf MT, Jeon S, Smith B, et al. The Yale Fitness Intervention Trial in female cancer survivors: Cardiovascular and physiological outcomes. Heart \& lung : the journal of critical care. Sep - Oct 2017;46(5):375-381.

61. Lipshultz SE, Adams MJ, Colan SD, et al. Long-term cardiovascular toxicity in children, adolescents, and young adults who receive cancer therapy: pathophysiology, course, monitoring, management, prevention, and research directions: a scientific statement from the American Heart Association. Circulation. Oct 22 2013;128(17):1927-1995.

62. Yeh JM, Ward ZJ, Chaudhry A, et al. Life Expectancy of Adult Survivors of Childhood Cancer Over 3 Decades. JAMA oncology. Jan 22020.

63. Reulen RC, Winter DL, Frobisher C, et al. Long-term cause-specific mortality among survivors of childhood cancer. Jama. Jul 14 2010;304(2):172-179.

64. Oeffinger KC, Mertens AC, Sklar CA, et al. Chronic health conditions in adult survivors of childhood cancer. The New England journal of medicine. Oct 12 2006;355(15):1572-1582.

65. Fidler MM, Reulen RC, Henson K, et al. Population-Based Long-Term Cardiac-Specific Mortality Among 34489 Five-Year Survivors of Childhood Cancer in Great Britain. Circulation. Mar 7 2017;135(10):951-963.

66. Feijen E, Font-Gonzalez A, Van der Pal HJH, et al. Risk and Temporal Changes of Heart Failure Among 5-Year Childhood Cancer Survivors: a DCOG-LATER Study. Journal of the American Heart Association. Jan 8 2019;8(1):e009122.

67. Yan AP, Chen Y, Henderson TO, et al. Adherence to Surveillance for Second Malignant Neoplasms and Cardiac Dysfunction in Childhood Cancer Survivors: A Childhood Cancer Survivor Study. Journal of clinical oncology : official journal of the American Society of Clinical Oncology. Mar 6 2020:JCO1901825. 
68. Smith WA, Li C, Nottage KA, et al. Lifestyle and metabolic syndrome in adult survivors of childhood cancer: a report from the St. Jude Lifetime Cohort Study. Cancer. Sep 1 2014;120(17):2742-2750.

69. Follin C, Thilen U, Osterberg K, Bjork J, Erfurth EM. Cardiovascular risk, cardiac function, physical activity, and quality of life with and without long-term growth hormone therapy in adult survivors of childhood acute lymphoblastic leukemia. The Journal of clinical endocrinology and metabolism. Aug 2010;95(8):3726-3735.

70. Silber JH, Cnaan A, Clark BJ, et al. Enalapril to prevent cardiac function decline in long-term survivors of pediatric cancer exposed to anthracyclines. Journal of clinical oncology : official journal of the American Society of Clinical Oncology. Mar 1 2004;22(5):820-828.

71. Lipshultz SE, Lipsitz SR, Sallan SE, et al. Long-term enalapril therapy for left ventricular dysfunction in doxorubicin-treated survivors of childhood cancer. Journal of clinical oncology: official journal of the American Society of Clinical Oncology. Dec 1 2002;20(23):4517-4522.

72. Gupta D, Lee Chuy K, Yang JC, Bates M, Lombardo M, Steingart RM. Cardiovascular and Metabolic Effects of Androgen-Deprivation Therapy for Prostate Cancer. Journal of oncology practice. Oct 2018;14(10):580-587.

73. Melloni C, Roe MT. Androgen deprivation therapy and cardiovascular disease. Urologic oncology. Feb 2020;38(2):45-52.

74. Melloni C, Nelson A. Effect of Androgen Deprivation Therapy on Metabolic Complications and Cardiovascular Risk. Journal of cardiovascular translational research. Dec 122019.

75. Agarwal M, Canan T, Glover G, Thareja N, Akhondi A, Rosenberg J. Cardiovascular Effects of Androgen Deprivation Therapy in Prostate Cancer. Current oncology reports. Aug 24 2019;21(10):91.

76. Zareba P, Duivenvoorden W, Leong DP, Pinthus JH. Androgen deprivation therapy and cardiovascular disease: what is the linking mechanism? Therapeutic advances in urology. Apr 2016;8(2):118-129.

77. Leong DP, Fradet V, Shayegan B, et al. Cardiovascular Risk in Men with Prostate Cancer: Insights from the RADICAL PC Study. The Journal of urology. Jan 3 2020:101097JU0000000000000714.

78. Melloni C SS, Blemings A, Goodman SG, Evans CP, Nilsson J, Bhatt DL, Zubovskiy K, Olesen TK, Dugi K, Clarke NW, Higano CS, Roe MT, on behalf of the PRONOUNCE Investigators. Cardiovascular Safety of Degarelix Versus Leuprolide for Advanced Prostate Cancer. JACC: CardioOncology. 2020;2(1):70-81. 


\section{FIGURES}

Figure 1. Representation of current evidence in cardiovascular disease prevention in patients with cancer.

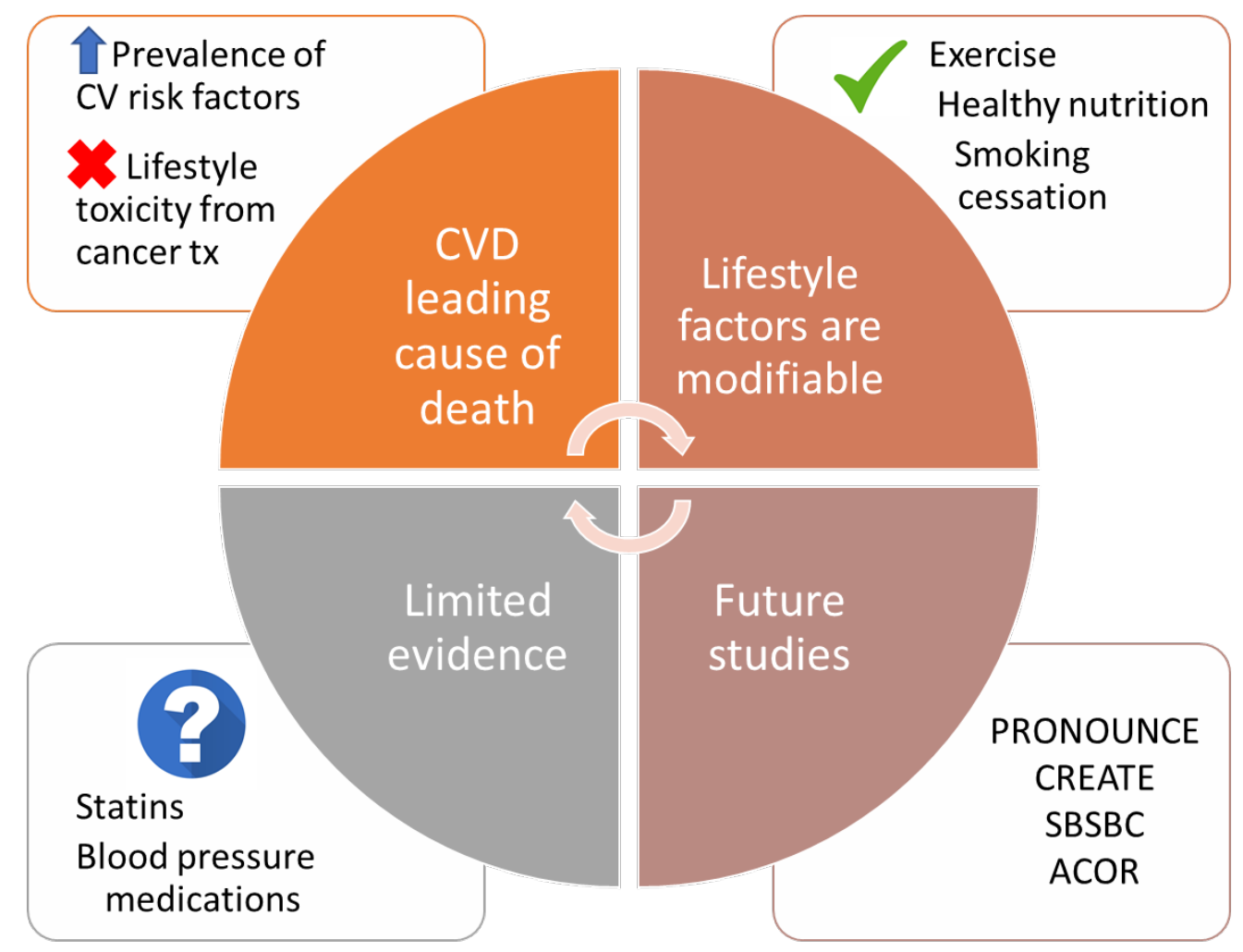

CV: cardiovascular; CVD: cardiovascular disease; tx: therapy; PRONOUNCE: Cardiovascular

Safety of Degarelix Versus Leuprolide for Advanced Prostate Cancer; CREATE: Caloric

Restriction and Exercise protection from Anthracycline Toxic Effects; SBSBC: Survival Benefits of Statin in Breast Cancer Patients; ACOR: Australia and New Zealand Cardio-Oncology Registry. 